\title{
Alternative Observers for SI Engine Air/Fuel Ratio Control
}

Hendricks, Elbert; Poulsen, Jannik; Olsen, Mads Bruun; Jensen, Per Buchbjerg; Føns, Michael; Jepsen, Christian

Published in:

Proc. 33rd IEEE Conf. on Decision and Control

Link to article, DOI:

10.1109/CDC.1996.573541

Publication date:

1996

Document Version

Publisher's PDF, also known as Version of record

Link back to DTU Orbit

Citation (APA):

Hendricks, E., Poulsen, J., Olsen, M. B., Jensen, P. B., Føns, M., \& Jepsen, C. (1996). Alternative Observers for SI Engine Air/Fuel Ratio Control. In Proc. 33rd IEEE Conf. on Decision and Control (Vol. 3, pp. 2806-2811). IEEE. https://doi.org/10.1109/CDC.1996.573541

\section{General rights}

Copyright and moral rights for the publications made accessible in the public portal are retained by the authors and/or other copyright owners and it is a condition of accessing publications that users recognise and abide by the legal requirements associated with these rights.

- Users may download and print one copy of any publication from the public portal for the purpose of private study or research.

- You may not further distribute the material or use it for any profit-making activity or commercial gain

- You may freely distribute the URL identifying the publication in the public portal

If you believe that this document breaches copyright please contact us providing details, and we will remove access to the work immediately and investigate your claim 


\title{
Alternative Observers for SI Engine Air/Fuel Ratio Control
}

\author{
Elbert Hendricks (eh@iau.dtu.dk), Jannik Poulsen, Mads Bruun Olsen, \\ Per Buchbjerg Jensen, Michael Føns and Christian Jepsen
}

\author{
Institute for Automation, Technical University of Denmark, DK-2800 Lyngby, DK
}

\begin{abstract}
In earlier work it has been shown that a nonlinear observer based on the use of the manifold pressure state equation and a nonlinear fuel film compensator can maintain accurate $\mathrm{A} / \mathrm{F}$ ratio control during both steady state and transient operation. This observer might be called a MAP (manifold absolute pressure) observer because it is fundamentally dependent on the use of the manifold pressure state equation and a MAP sensor. It is in reality a constant gain extended Kalman filter (CGEKF). While this observer shows promise for some applications, it obviously cannot immediately be used with other air mass flow sensors than a MAP sensor. In this paper it is shown that it is possible to construct a family of alternative nonlinear observers which "naturally" allow the use of any given air mass flow related sensor or a combination of them for $A / F$ ratio control. This new family of observers provides the SI engine control system designer with a variety of robust control systems which can easily be made redundant in order to satisfy newer engine emissions and diagnosis requirements and legislation.
\end{abstract}

\section{Introduction}

The control of the air/fuel ( $\mathrm{A} / \mathrm{F})$ ratio of spark ignition (SI) engines is not a trivial control problem as it involves the coordinated measurement (or estimation) of the air flow and the control of the fuel flow in order to maintain a fixed $\mathrm{A} / \mathrm{F}$ ratio. This is necessary for modern engines using three way catalysts (TWC) in order to minimize emissions. The accuracy required is on the order of $+/-0.5 \mathrm{~A} / \mathrm{F}$ ratio (or about $+/ .3 .5 \%$ with respect to stoichiometric operation, lambda $=1$ ). When using conventional engine A/F ratio control systems, this is an especially difficult task during fast throttle angle and load transients [1]

There are three main reasons why this problem is so difficult to solve: 1. manifold filling can give rise to a large spike in the air flow to the engine during throttle opening, 2 . there is a large amount of noise in the air mass flow related ( $\Lambda$ MFR) sensor signals due to engine pumping [2] and 3 . fuel must be injected into the intake manifold with the proper time response so as to avoid the effects of manifold fuel wetting [3]. Such AMFR sensors might be a manifold absolute pressure sensor (MAP) or a throttle mass air flow sensor (MAF). A conventional throttle air mass flow sensor will be called a MAFt sensor in what follows to avoid confusion. This paper will be mostly concerned with the solution of problems 1 . and 2 . as a practically applicable solution to 3 . has been found [3].

In conjunction with properly designed fuel film compensators, more advanced nonlinear observer based control systems have much better performance than conventional control systems but currently require a certain selection of air mass flow related engine sensors. For example the MAP CGEKF observer in [3] requires a MAP sensor and the feedforward MAF observer in [4] entails the use of a hot wire MAFt sensor. The general problem of using any given sensor or a combination of them in an observer based A/F ratio control has yet to be attacked. Moreover the use of engine port air mass flow sensors has not been considered even though such sensors may soon be available [5]. Redundant sensor compliments are attractive as they have built in robustness properties and make possible necessary diagnostic functions. Such control systems have yet to be presented in the literature.

This paper is concerned with the derivation and testing of a new set of
SI engine observers which are model based and which are applicable to any or all of the currently or possibly available engine air mass flow related (AMFR) sensors. These observers are "natural" in the same sense as the MAP observer in [3], i. e., the observed variable is the same as the independent estimated variable in the observer state equation and they are emerge from basic physical theory. Moreover it is shown that these observers have good noise rejection properties and give accurate $\mathrm{A} / \mathrm{F}$ ratio control, both in the steady state and for fast transients. Only systems with a mechanical connection between the throttle plate and the accelerator pedal are considered here; these are the most common systems currently in use and are currently the least expensive.

\section{The Revised Mean Value Engine Model}

Recently an improved version of the Mean Value Engine Model (MVEM) prescnted earlicr [6] has been reported in the literature [7]. This model is physically hased and has been shown to be valid both for steady state and fast transient engine operation. The main difference between the revised model and the earlier one is that the revised model is more physical and contains fewer fitting parameters. It is also easy to fit it to other engines without the use of more than a few measurement points. This is in contrast to many well known regression equation dynamic engine models which require a complete engine mapping and have a very large number of fitting parameters [8], [9], [10].

The main dynamic equation of the revised MVEM with respect to A/F ratio control is the manifold pressure state equation

$$
\dot{\mathrm{p}}_{\mathrm{i}}=\frac{\mathrm{RT} \mathrm{T}_{\mathrm{i}}}{\mathrm{V}_{\mathrm{i}}}\left(-\mathrm{m}_{\mathrm{ap}}+\mathrm{m}_{\mathrm{at}}\right)=\mathrm{f}_{3}\left(\alpha, \mathrm{n}, \mathrm{p}_{\mathrm{i}}\right)
$$

where $p_{i}$ and $T_{i}$ are the intake manifold absolute pressure (MAP) and temperature respectively, $\mathrm{R}$ is the gas constant, the quantities in the parenthesis are the port and throttle plate air mass flows respectively while $\alpha$ is the throttle angle and $n$ the crank shaft speed.

The port air mass flow is a weak function of the crank shaft speed and a strong function of the intake manifold pressure (i. e.. $m_{\mathrm{ap}}=\mathrm{m}_{\mathrm{ap}}\left(\mathrm{n}, \mathrm{p}_{\mathrm{i}}\right)$ ) and the air mass flow past the throttle plate is a function of the throttle angle and the intake manifold pressure (i. e., $m_{u 1}=m_{a i}(\alpha, p)$ ). These functions are algebraic functions because the equilibrium of the air mass flow is established rapidly (within a few milliseconds) and this time is much less than the time scale on which the crank shaft speed can change (a few seconds) or the minimun operator throttle reaction time (about a tenth of a second) [6]

The port air mass flow is given by the speed-density equation

$$
m_{a p}\left(n, p_{i}\right)=\frac{V_{d}}{120 R T_{i}}\left(e_{v}{ }^{\prime} p_{i}\right) n=\frac{V_{d}}{120 R T_{i}}\left(s_{i}(n) p_{i}+y_{i}(n)\right) n
$$

where $s_{i}$ and $y_{i}$ are weak functions of $n$. The quantity in the large parenthesis on the right is proportional to the air charge per stroke. The validity of equation (2) is established in [7] for 5 different engines. For use in an observer, $s_{i} \approx 0.95$ and $y_{i} \approx-0.08$ are effectively constants. Both of these fitting constants and the form of equation (2) can be derived from physical considerations of the pumping cycle of an SI engine [7]

A physical model for the air mass flow past the throttle plate can be found by considcring the dominant and subordinate flow paths through it. 
The dominant flow path is that past the down stream edge of the throttle plate and the subordinate path is past its up stream edge. The total flow is of course the sum of that through the dominant and subordinate flow paths. Because of the very rapid flow through the dominant flow path, the pressure difference across the two flow paths is slightly different. Assuming isentropic flow through the two flow paths and no pressure recovery, a physical expression for the flow through the throttle plate can be found. In [7] it is shown that this expression agrees very accurately with careful measurements which have been made on a model throttle plate and with data on two experimental engines. Engine pumping fluctuations do not make any great difference to the overall flow picture and thus a physical expression for the air mass flow through the throttle plate has been found and verified. While this expression is accurate, it has an inconvenient and complicated form.

In order to find a simple and compact equation for the air mass flow past the throttle plate, a fit has been made to the physical model. This fit is as follows:

$$
\begin{aligned}
& \beta_{1}(\alpha)=1-\alpha_{1} \cos (\alpha)+\alpha_{2} \cos ^{2}(\alpha) \\
& \beta_{2}\left(p_{r}\right)=\left\{\begin{array}{cc}
\frac{1}{p_{n} \sqrt{p_{r}^{p_{1}}-p_{r}^{p_{2}}},} & \text { if } p_{r} \geq p_{c} \\
1, & \text { if } p_{r}<p_{c}
\end{array}\right. \\
& p_{c}=\left[\frac{p_{1}}{p_{2}}\right]^{\left.\left(1 / p_{2}-p_{1}\right)\right)}, p_{n}=\sqrt{p_{c}^{p_{1}}-p_{c}^{p_{2}}}
\end{aligned}
$$

where $p_{r}=p_{i} / p_{a}, p_{a}$ is the pressure just in front of the throttle plate and $p_{c}$ is the critical pressure ratio. Notice that $p_{n}$ is only a normalization constant which gives $\beta_{2}$ a value of 1 at low manifold pressures. This is convenient for modelling purposes. The following constants have been found to fit a model throttle plate, a modern 4 valve per cylinder, four cylinder, and an older, 2 valve per cylinder, 4 cylinder engine: $\alpha_{1}: 1.4073$, $\alpha_{2}: 0.4087, p_{1}: 0.4404, p_{2}: 2.3143, p_{n}: 0.7404$ and $p_{\mathrm{s}}: 0.4125$. It is thus thought that the expression above will be generally applicable to a number of SI engines. It should be noted in equation (3) that the critical pressure ratio is 0.4125 instead of the usual 0.528 . The reason for this is the two flow path model for the throttle plate air mass flow [7]. Note that in a real engine, $p_{r}$ is always less than one due to pressure losses in the air filter and associated ducting and possibly an air flow sensor.

The overall throttle air mass flow in the modified MVEM is given by the equation

$$
\mathrm{m}_{\mathrm{at}}\left(\alpha, \mathrm{p}_{\mathrm{r}}\right)=\mathrm{m}_{\mathrm{pTa}} \beta_{1}(\alpha) \beta_{2}\left(\mathrm{p}_{\mathrm{r}}\right)
$$

where $\mathrm{m}_{\mathrm{pTs}}=\mathrm{m}_{\mathrm{at} 1}\left(\mathrm{p}_{\mathrm{a}} / \mathrm{T} \mathrm{T}\right)$ and the fitting constant is $\mathrm{m}_{\mathrm{at} \mid}$. In equation (4) the pressure and temperature of the ambient air have been taken into account explicitly.

Apart from simplifying the model calibration procedure, the main influence of the model revisions is to increase its accuracy in the low and medium power ranges. The standard deviation of the model error is less than $2 \%$ from the idle speed region to wide open throttle (WOT) operating conditions. This accuracy is achieved both for steady state and for transient operation during fully warm operation. This accuracy is sufficient for closed loop observer applications and may be improved by taking into account the $n$ dependence in equation (2) if desired [7].

\section{Derivation of the Nonlinear Observer Equations}

The purpose of the observer in air/fuel control is as a smoother and predictor for the air mass flow. In a throttle body injection system the throttle air mass flow has to be estimated while in a multipoint injection system the port air mass flow is the variable which must be found. Such smoothing or estimation is necessary because of the large event periodic pumping fluctuations which are a part of the induction process [2], the time constants of the sensor(s) and modelling error. Apart from these problems, the observer also has the purpose of compensating for the thermal perturbations which must come because of backflow and the variability of combustion.

Observers may be of two types: open loop (or feedforward) ([11], [12], [13]) and closed loop. Closed loop here implies direct use of the difference between the estimate(s) and measurement(s) (or innovations) in the observer equation(s) [3]. Clearly the closed loop observer is to be preferred as it gives a direct compensation for modelling error, thermal perturbations and a direct smoothing of the pumping noise. Moreover it is easy to construct and straight forward to analyze. For these reasons only closed loop observers are to be considered in this paper. Also only estimators for the air mass flow related (AMFR) sensors are to be treated.

In general for automotive applications control systems are for reasons of cost most often based on the use of only a one air mass flow related sensor at a time. This fact of life and the fact that the manifold pressure state equation is the only differential equation which is known to describe the air mass flow into an engine has limited the closed loop observers which can be built for $\mathrm{A} / \mathrm{F}$ ratio control to a MAP observer of the type derived in [3]. This "natural" observer uses a MAP sensor and an observer equation based on the manifold pressure state equation

$$
\dot{\hat{p}}_{i}=f_{3}\left(\alpha, n, \hat{p}_{i}\right)+k_{33}\left(p_{i m}-\hat{p}_{i}\right)
$$

where equation (1) has been used, the hats denote estimates, the " $m$ " subscript denotes the measurement and $k_{33}$ is the Kalman gain. The throttle angle, $\alpha$, and the crank shaft speed, $n$, are actually inputs to the observer but of course in a real system would be measured using the relevant sensors. This observer is "natural" in the sense that the estimated manifold pressure is the same as the variable being measured. As documented experimentally in [3] this observer works quite well as an air mass flow estimator.

The air mass flow which must be estimated is that at the injector(s) location. Given the manifold pressure estimate from equation (5), the estimated air mass flow is given by equation (2) for a port injected engine and by equation (4) for a throttle body injected engine. These estimated air mass flows are used in the basic engine fueling calculation: $m_{\mathrm{fi}}=\mathrm{m}_{\mathrm{ax}} /\left(\lambda_{\mathrm{des}} \mathrm{L}_{\mathrm{th}}\right)$ where $\mathrm{x}=\mathrm{p}$ or $\mathrm{t}, \lambda_{\mathrm{des}}$ is the desired lambda value (usually 1 ) and $L_{t h}$ is the stoichiometric normalization factor, 14.7. Given this desired fuel flow at the engine intake port, the fueling dynamics in the intake manifold must be compensated for in order to insure that the mixture is correct when it reaches the intake port. This can be accomplished by using a nonlinear transient film fuel compensator (NTFC) on the basic calculated fuel flow as reported in [3].

In order to construct "natural" observers for the throttle plate and port air mass flows it is first necessary to derive differential equations for these variables. If only one of the AMFR sensors is to be used at a time, these differential equations must involve only the measured variable and the state variable. If different combinations of AMFR sensors are used then the presence of more than one AMFR variable should be allowed in the observer equations.

\subsection{Throttle Air Mass Flow Differential Equation}

The most common throttle air mass flow sensors currently in use are hot wire sensors. Such sensors have response times and nonlinearities which must be taken into account in an observer design ([2], [3], [11]) but will be ignored here for the sake of simplicity. In the experimental portion of this work a very fast, linear, and accurate laminar flow meter will be used for this sensor to avoid the complications introduced by imperfect sensors. For the sake of brevity a throttle air mass flow sensor will be called a MAFt (Mass Air Flow, throttle) sensor in what follows.

In order to derive a differential equation for the throttle air mass flow it is convenient to use equation (4) above. This equation gives the steady state solution for the required state variable. A differential equation for this variable can be found simply by differentiating equation (4) and remembering that the crank shaft speed derivative can be neglected (as the crank shaft speed changes relatively slowly). Symbolically the result of 
this calculation is seemly complex: it is

$$
\begin{aligned}
& \dot{\mathrm{m}}_{\mathrm{a} t}=\mathrm{m}_{\mathrm{pTa}}\left[\beta_{1}^{\prime}(\alpha) \beta_{2}\left(\mathrm{p}_{\mathrm{r}}\right) \dot{\alpha}+\beta_{\mathrm{l}}(\alpha) \beta_{2}^{\prime}\left(\mathrm{p}_{\mathrm{r}}\right) \frac{\dot{\mathrm{p}}_{\mathrm{i}}}{\mathrm{p}_{\mathrm{a}}}\right] \\
& =m_{p T a}\left[\beta_{\alpha^{\prime}}\left(\alpha, p_{t}\right) \dot{\alpha}+\beta_{p^{\prime}}\left(\alpha, p_{i}\right) \frac{R T_{i}}{p_{a} V_{i}}\left(-m_{a p}\left(n, p_{i}\right)+m_{a 1}\right)\right]^{(6} \\
& =f_{41}\left(\alpha, n, p_{i}, m_{a t}\right) \\
& =\mathrm{m}_{\mathrm{p} \mathrm{Ta}_{\mathbf{a}}}\left(\beta_{\alpha^{\prime}}\left(\alpha, \mathrm{m}_{\mathrm{st}}\right) \dot{\alpha}\right. \\
& \left.+m_{\mathrm{TVi}} \beta_{\mathrm{p}}\left(\alpha, \mathrm{m}_{\mathrm{at}}\right)\left(-\mathrm{m}_{\mathrm{ap}}\left(\mathrm{n}, \mathrm{m}_{\mathrm{at}}\right)+\mathrm{m}_{\mathrm{at}}\right)\right) \\
& =f_{42}\left(\alpha, n, m_{a t}\right)
\end{aligned}
$$

for $p_{r}>p_{c}$, where the substitutions $p_{i}=\beta_{2}{ }^{-1}\left(m_{a r} / m_{a t 0} \beta_{1}(\alpha)\right)$ and $p_{r}=p_{i} / p_{a}$ have been used and where the primes in the first equation indicate partial derivatives with respect to the arguments in the parenthesis. $\beta_{\alpha^{*}}=\beta_{1}{ }^{\prime} \beta_{2}$, $\beta_{p^{\prime}}=\beta_{1} \beta_{2}$, and $m_{\mathrm{TV}_{\mathrm{i}}}=\mathrm{RT}_{\mathrm{j}} /\left(\mathrm{p}_{\mathrm{a}} \mathrm{V}_{\mathrm{i}}\right)$.

When $p_{r}<p_{c}$ then equation (6b) above becomes

$$
\dot{\mathrm{m}}_{\mathrm{at}}=\frac{\beta_{1}^{\prime}(\alpha)}{\beta_{1}(\alpha)} \mathrm{m}_{\mathrm{at}} \dot{\alpha}=\mathrm{f}_{42}\left(\alpha, \mathrm{m}_{\mathrm{st}}\right)
$$

the "beta" functions on the right in the last two equations above are clearly simple functions of $\alpha$ and the air mass flow past the throttle plate. If only throttle angle, MAFt, crank shaft speed, ambient pressure and ambient temperature sensors are used then equations $(6 \mathrm{~b})$ and $(6 \mathrm{c})$ above are the desired differential equation.

While equations (6a), (6b) and (6c) above seem to be complex, they are in reality easily represented in simple tables (or products of tables), some of which are the same. Moreover these tables may be generated from the algebraic expression in equations (2) and (3) or their derivatives. If higher accuracy is desired, they may be generated by direct engine mapping though this is not thought to be necessary for most applications.

In order to test the differential equation above, a number of experiments were conducted on a throttle body injected (TBI or CFI) $1275 \mathrm{cc}$ British Leyland engine mounted on a dynamometer. This is a 4 cylinder engine with two valves per cylinder and two Siamesed intake ports. The throttle body air mass flow was measured with a laminar flow meter mounted directly in front of the engine air filter. Tests were conducted over the entire operating range of the engine from idle speed to WOT. Using small and large signal step testing around many operating points, as in [7], it was shown that the differential equation is accurate both for the steady state and during the rapid throttle movements. The overall accuracy displayed was a little worse than that of the basic model, on the order of $+/-3 \%$ (standard deviation of the relative prediction error) over the given operating range.

\subsection{Port Air Mass Flow Differential Equation}

In order to find the differential equation for a port air mass flow sensor, onc can proceed by differentiating equation (2), again remembering that the crank shaft speed derivative can be neglected. The result is

$$
\begin{aligned}
\dot{m}_{\text {ap }} & =\frac{V_{d}}{120 R T_{i}} \frac{d}{d t}\left(s_{i} p_{i}+y_{i}\right) n \\
& =\frac{V_{d} s_{i} n}{120 R T_{i}} \dot{p}_{i} \\
& =f_{51}\left(\alpha, n, p_{i}, m_{\text {ap }}\right)
\end{aligned}
$$

$$
\begin{aligned}
& =m_{n T i}\left(-m_{a p}+m_{p T a} \beta_{1}(\alpha) \beta_{2}\left(m_{a p}, n\right)\right) \\
& =f_{52}\left(\alpha, n, m_{a p}\right)
\end{aligned}
$$

where $\mathrm{m}_{\mathrm{nTi}}=\mathrm{s}_{\mathrm{i}} \mathrm{V}_{\mathrm{d}} \mathrm{n} /\left(120 \quad \mathrm{~V}_{\mathrm{i}}\right)$ and the substitution $\mathrm{p}_{\mathrm{i}}=$ $\left(1 / s_{i}\right)\left(m_{a p}\left(120 R T_{i} /\left(V_{d} n\right)\right)-y_{i}\right)$ has been used. The last differential equation can be used to predict the port air mass flow if throttle angle, port air mass flow (MAFp), crank shaft speed, and ambient pressure and temperature sensors are used. Otherwise a MAP sensor will also be required. As earlier, while the algebraic functions necessary to solve the differential equation above are apparently complex, they are easy to generate with an accuracy sufficient for observer construction purposes.

Testing of the port flow differential equation was conducted with a newly developed type of port flow sensor. Such a sensor is of course desirable because it is capable of measuring the air mass flow at the desired injection location. Without going into too much detail, this sensor has a response time of about 1 millisecond, is bi-directional and can be linearized with good accuracy. For convenience this sensor is called a MAFp sensor in this paper. Two such sensors were calibrated against each other and against an accurate laminar flow meter on an experimental engine. These sensors were then used to check the model predictions of equation (7). The experimental setup was as described above except that $1275 \mathrm{cc}$ British Leyland was in this case provided with a specially designed port injection manifold with Siamesed intake ports. Four injectors are used, one for each engine intake valve. The two MAFp sensors (which are quite small) were inserted just upstream of the port injectors in the two intake runners and their outputs added to find the total port air mass flow. Again, the basic accuracy of the dynamic model is of the same order as that exhibited by the throttle air mass flow differential equation: the standard deviation of the relative error is below $3 \%$ over the operating range of the engine.

\subsection{Observer Configuration and Sensor Selection}

The actual configuration of the observers which can be constructed on the basis of the differential equations above is dependent on the sensor selection. Sensors for the throttle angle and crank shaft speed are obviously necessary in any case as well as the ambient and intake manifold temperatures. Apart from these "input" variables the state variable (or variables) which is (are) to be estimated in an observer should correspond to the air mass flow related sensor(s) which is (are) used. This means that the following AMFR sensor types lead to the following observer configurations:

a. MAP sensor: equation (5)

b. MAFt sensor:

$$
\dot{\hat{\mathrm{m}}}_{\mathrm{st}}=\mathrm{f}_{42}\left(\alpha, \mathrm{n}, \hat{\mathrm{m}}_{\mathrm{at}}\right)+\mathrm{k}_{\mathrm{s} A}\left(\mathrm{~m}_{\mathrm{utm}}-\dot{\mathrm{m}}_{\mathrm{at}}\right)
$$

c. MAFp sensor:

$$
\dot{\mathrm{m}}_{\mathrm{ap}}=\mathrm{f}_{52}\left(\alpha, \mathrm{n}, \hat{\mathrm{m}}_{\mathrm{ap}}\right)+\mathrm{k}_{55}\left(\mathrm{~m}_{\mathrm{apm}}-\hat{\mathrm{m}}_{\mathrm{ap}}\right)
$$

where $k_{33}, k_{44}$, and $k_{55}$ are the kalman gains.

In addition to these single equation observer types, it is straight forward to construct observer configurations which include doubly redundant AMFR sensor complements:

\section{d. MAP and MAFt sensors:}

$$
\left[\begin{array}{c}
\dot{\hat{p}}_{\mathrm{i}} \\
\dot{\mathrm{m}}_{\mathrm{at}}
\end{array}\right]=\left[\begin{array}{c}
\mathrm{f}_{3}\left(\alpha, \mathrm{n}, \hat{\mathrm{p}}_{\mathrm{i}}\right) \\
\mathrm{f}_{41}\left(\alpha, \mathrm{n}, \hat{\mathrm{p}}_{\mathrm{i}}, \hat{\mathrm{m}}_{\mathrm{at}}\right)
\end{array}\right]+\mathrm{K}_{34}\left[\begin{array}{c}
\mathrm{p}_{\mathrm{im}}-\hat{\mathrm{p}}_{\mathrm{i}} \\
\mathrm{m}_{\mathrm{atm}}-\hat{\mathrm{m}}_{\mathrm{at}}
\end{array}\right]
$$


e. MAP and MAFp sensors:

$$
\left[\begin{array}{c}
\dot{p}_{i} \\
\dot{m}_{\mathrm{ap}}
\end{array}\right]=\left[\begin{array}{c}
\mathrm{f}_{3}\left(\alpha, \mathrm{n}, \hat{\mathrm{p}}_{\mathrm{i}}\right) \\
\mathrm{f}_{5 \mathrm{II}}\left(\alpha, \mathrm{n}, \hat{\mathrm{p}}_{\mathrm{i}}, \hat{\mathrm{m}}_{\mathrm{ap}}\right)
\end{array}\right]+\mathrm{K}_{35}\left[\begin{array}{c}
\mathrm{p}_{\mathrm{im}}-\hat{\mathrm{p}}_{\mathrm{i}} \\
\mathrm{m}_{\mathrm{apm}}-\hat{\mathrm{m}}_{\mathrm{ap}}
\end{array}\right]
$$

f. MAFt and MAFp sensors:

$$
\left[\begin{array}{c}
\dot{\mathrm{m}}_{\mathrm{at}} \\
\dot{\mathrm{m}}_{\mathrm{up}}
\end{array}\right]=\left[\begin{array}{l}
\mathrm{f}_{42}\left(\alpha, \mathrm{n}, \hat{\mathrm{m}}_{\mathrm{at}}\right) \\
\mathrm{f}_{52}\left(\alpha, \mathrm{n}, \hat{\mathrm{m}}_{\mathrm{ap}}\right)
\end{array}\right]+\mathrm{K}_{45}\left[\begin{array}{l}
\mathrm{m}_{\mathrm{atm}}-\hat{\mathrm{m}}_{\mathrm{at}} \\
\mathrm{m}_{\mathrm{apm}}-\hat{\mathrm{m}}_{\mathrm{ap}}
\end{array}\right]
$$

where $K_{34}, K_{35}$ and $K_{45}$ are $2 \times 2$ Kalman gain matrices

Finally it is clear that it is possible to construct a triply redundant set of observer equations using all three sensors:

g. MAP, MAFt and MAFp sensors:

$$
\left[\begin{array}{c}
\dot{\mathrm{p}}_{\mathrm{i}} \\
\dot{\hat{\mathrm{m}}}_{\mathrm{at}} \\
\dot{\mathrm{m}}_{\mathrm{ap}}
\end{array}\right]=\left[\begin{array}{c}
\mathrm{f}_{3}\left(\alpha, \mathrm{n}, \hat{\mathrm{p}}_{\mathrm{i}}\right) \\
\mathrm{f}_{41}\left(\alpha, \mathrm{n}, \hat{\mathrm{p}}_{\mathrm{i}}, \hat{\mathrm{m}}_{\mathrm{at}}\right) \\
\mathrm{f}_{51}\left(\alpha, \mathrm{n}, \hat{\mathrm{p}}_{\mathrm{i}}, \hat{\mathrm{m}}_{\mathrm{ap}}\right)
\end{array}\right]+\mathrm{K}_{345}\left[\begin{array}{c}
\mathrm{p}_{\mathrm{im}}-\hat{\mathrm{p}}_{\mathrm{i}} \\
\mathrm{m}_{\mathrm{atm}}-\hat{\mathrm{m}}_{\mathrm{at}} \\
\mathrm{m}_{\mathrm{spm}}-\hat{\mathrm{m}}_{\mathrm{ap}}
\end{array}\right]
$$

where $K_{345}$ is a 3 x 3 Kalman gain matrix

While it is quite possible to construct the observers above with the given sensors, which observer is to be used depends also on the injector configuration. This is of course because the purpose of the observer is to estimate the air mass flow at the injector(s) location(s). Given the correct

estimate, the desired fuel for the engine is $m_{f u}=m_{a x} /\left(\lambda_{\text {des }} L_{i b}\right)$, where

$x=p$ or $t$ for port or throttle body injection. In order to insure that this fuel is available at the intake port, a NTFC filter must be used. Also if the air mass flow is estimated at a different location than that at which a measurement is made, then it may be necessary to insert a time delay corresponding to the air mass flow transport time [1]. For example, if the air mass flow is measured in front of the throttle plate and a port injection system is used, then the injection signal has to be delayed a time corresponding to the air transport time from the MAFt sensor to the port injectors.

It should be noted that the multiple sensor observers above are naturally redundant and the failure of a single sensor will not lead to engine control system malfunction. Moreover sensor measurements can be checked against each other and an exhaust lambda sensor for diagnostic purposes.

\subsection{Observer Gain Selection and Realization}

In order for the observers above to be used in a real time system it is necessary to choose the proper observer gain(s) and to integrate the observer differential equations in real time. Both of these problems have been treated before in [14] for an observer like those described above. The gains are selected in order to satisfy the nondivergence criteria given in [15]. In order to use this criteria, the noise properties of the system have to be known which have been treated in [2] and [3]. It must be taken into account that the noise waveform is sinusoidal and that there is strong correlation between the different AMFR sensor states. When designed according to these details, the observer has significant robustness properties.

The integration of the observer equations can be accomplished using a specially designed three stage, first order, explicit Runge-Kutta numerical integration method (NIM) [14]. While more complex than a more common integration method this NIM has an extended stability region which allows a larger sampling period than would ordinarily be the case. This is necessary because the smallest effective time constant can be below $0.4 \mathrm{msec}$.

\subsection{Compensation for the Fuel Film Dynamics}

In order to compensate for the fueling dynamics, the following first order, nonlinear compensator was used (which is derived in [3]):

$$
m_{\mathrm{fi}}=\frac{1}{1-X}\left(m_{f u}-m_{i f}\right)
$$

where the fuel film flow, $\mathrm{m}_{\mathrm{fr}}$ is obtained from solving

$$
\dot{m}_{\mathrm{ff}}=\frac{1}{\tau_{\mathrm{f}}}\left(-\mathrm{m}_{\mathrm{ff}}+X \mathrm{~m}_{\mathrm{fi}}\right)
$$

Using the step fuel identification technique detailed in [3] it was found that "tau" parameter is about $0.6 \mathrm{sec}$ and $0.25 \mathrm{sec}$ for the CFI and MPI manifolds respectively. In the same way the " $\mathrm{X}$ " parameter was found to be a function of operating point, i. e., $X=X\left(n, p_{i}\right)$. It was realized as a two dimensional $(6 \times 6)$ table for the work here. $X$ was of course different for the CFI and MPI manifolds. The compensation obtained in this way for the fueling dynamics was quite acceptable for the purposes of testing the observers but further accuracy could be obtained by using a higher order compensator and/or more elaborate identification techniques.

\section{Experimental Results}

In order to test the observers above, experiments were conducted the $1275 \mathrm{cc}$ British Leyland engine mentioned above. Both CFI and MPI injection manifolds were available for this engine. Apart from the relevant temperature sensors, this engine was equipped with throttle position sensor, crank shaft speed and MAP, MAFt and MAFp sensors for both the CFI and MPI manifolds. Relevant temperatures were also measured. The signals for the two MAFp sensors in the MPI manifold were added together electronically to obtain the total port air mass flow to the engine because of the Siamesed intake ports.

To realize the observer control a 486 PC Engine Control Development System (ECDS) built at DTU was available. This system is a further development of an earlier ECDS described in the literature [16]. This system makes measurements via an $\mathrm{A} / \mathrm{D}$ card in the expansion slot of the $\mathrm{PC}$ and control is possible via a D/A card in the same machine. The observers were realized in a specially developed multi-tasking system and were programmed in Pascal. The nonlinear compensator mentioned above was programmed into the ECDS system together with the observers to be tested. The ECDS system is very fast and allows a sampling time of down to $0.5 \mathrm{msec}$ when running the observer(s), the compensator and controlling the engine fuel and spark. Sampling times used in the testing varied between 1 and $4 \mathrm{msec}$, depending upon whether or not the port air mass flow sensors were used.

To test the observers' control capabilities, fast throttle angle transients were applied to the engine under various loading conditions. The object of the tests was to show that the observer control can make possible accurate control of the A/F ratio during transients and also in steady state. The target control interval for lambda was $1+/-3.5 \%$ corresponding to an A/F ratio (AFR) of $14.7+/ .1 / 2$ AFR, which is generally that considered necessary. It is clear that both the air and fueling calculations as well as the NTFC must be accurate in order to achicve good overall AFR control.

Notice that most of the important engine variables are plotted on the following figures so that the level of excitation can be judged. The parallel lines on the lambda plot (the last one in each series) represent the $+/-1 / 2$ and $+/-1$ AFR control limits. Where relevant, the measured variables are shown shaded (or rastered) to distiguish them from the estimated variables in black. Space limitations prevent the presentation of results for all of the injector/observer configurations outlined above. For this reason only results for two combinations will be treated.

Figure 1 shows the preformance of MAP/MAFt observer with a CFI injection manifold. Good AFR control accuracy ( $/ /-1 / 2$ AFR) is demonstrated over a large operating range in spite of large throttle angle and engine speed transients. It is also capable of handling large tip-in/out/-in transients as well as large levels of pumping fluctuations. Manifold filling spikes are apparent in the initial peaks in the throttle air mass flow. 

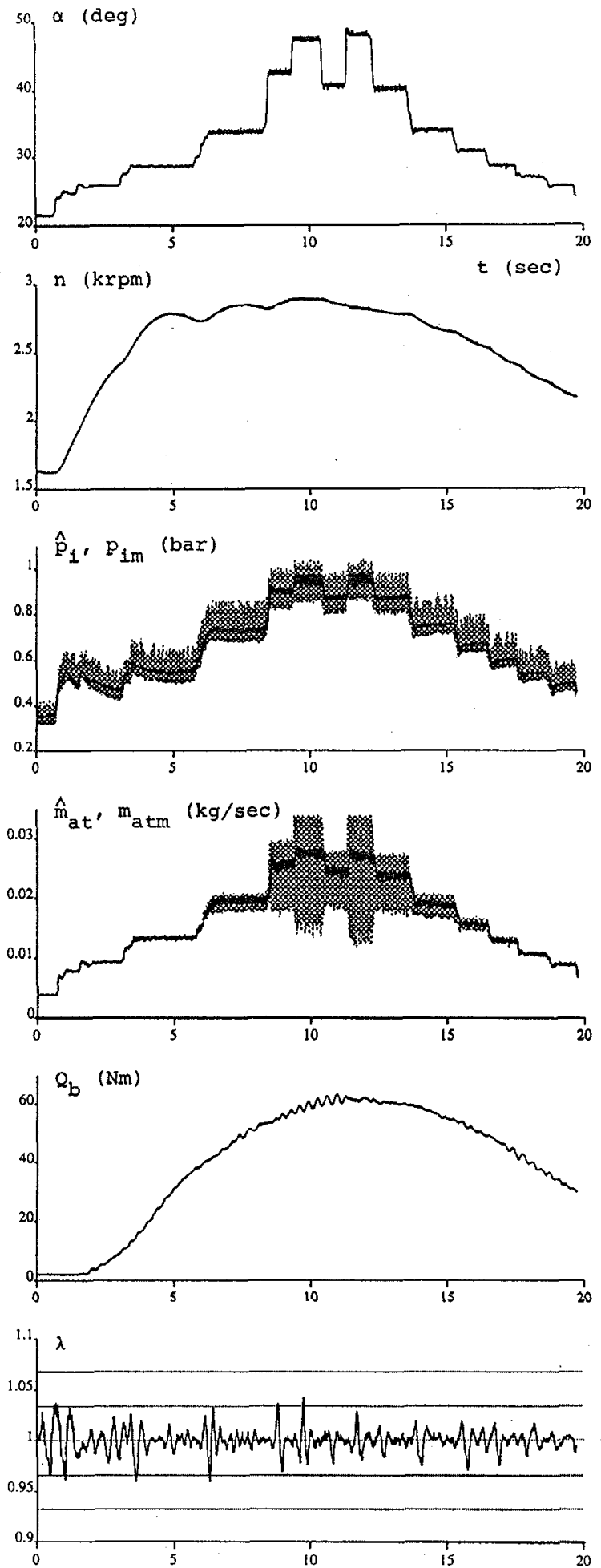

Figure 1. AFR control accuracy of the MAP/MAFt observer (CFI engine)

Figure 2 shows the performance ot the MAP/MAFp observer with the MPI manifold for a throttle angle input close to that of the previous figure at approximately the same operating point. Because of the large level of the fluctuations in the port air mass flow, the measured $m_{\mathrm{ap}}$ signal is not shown directly: only its event average (shaded). It is seen to agree closely with the observer estimate. Because the direct MAFp sensor measurement, a more accurate estimate of the port air mass flow is possible and there is no manifold filling to be compensated for. Moreover
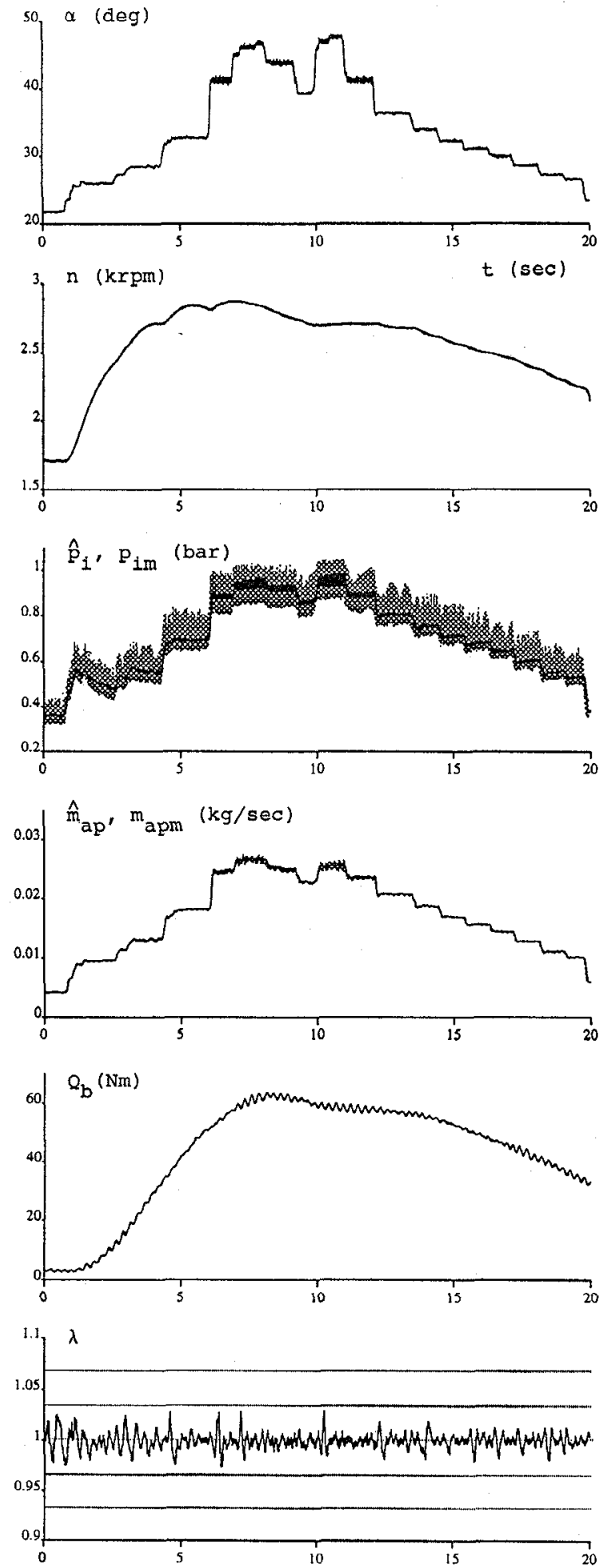

Figure 2. AFR control accuracy MAP/MAFp observer (MPI engine).

the manifold wetting is less serious because it takes place over a smaller area at a more uniform temperature. Thus the AFR control performance is somewhat better than in figure 1: lambda $=1+/-2.5 \%$ accuracy is apparent.

While it cannot be shown here, experimental tests show that the single and multiple observer equations given in this paper work more or less equally well, independent of which is selected, given the availability of a suitably accurate sensor. This is of course to be expected as good AFR 
control accuracy has been demonstrated with a single sensor [3]. Multiple equation observers contain redundant air flow information.

The figures above show that the basic concept of the "natural" family of air mass flow estimators derived in this paper is valid over a large engine operating range. Obviously a great deal of experimentation will be necessary in order to show which of the members of the family are the most advantageous for practical applications given the performance/cost and emission limit tradeoffs which must be satisfied in the future.

\subsection{Discussion}

For a throttle angle input similar to that used in this work, a conventional AFR control system has transient peaks which are typically on the order of $+/-2$ to 3 AFR. A recently presented sliding mode controller shows peak variations of $+1-1 / 2$ AFR but with a throttle angle input about 5 times smaller than that used here ( 10 degree square waves) [17]. Using a neural network in the NTFC and an open loop observer, the authors in [18] have recently demonstrated a control accuracy of $+/-1$. AFR for a throttle angle input like that used here. A lambda control loop is also used in this work. Somewhat more accurate control is possible using a drive-by-wire throttle control and a fairly elaborate observer (4 states), +/- 0.3 AFR units, as demonstrated in [19]. This system is constructed so that the throttle does not move during the time that air flow related measurements are made. It also uses an adaptive loop to "tune" the observer on line and in this way an AMFR sensor is not necessary.

Thus the AFR control performance achieved here is on the same level or is better than that which is possible with other observer based systems reported in the literature but it has built in reliability in the form of sensor redundance. Better performance is possible using an external lambda control loop with or without an exhaust lambda observer as in [19].

\section{Conclusions}

A family of alternative "natural" nonlinear observers has been derived for on-line air mass flow estimation. This family is "natural" in two senses: 1 . the observer equations emerge naturally from the physical model of the system, 2 . the observer form found is conventional so that the error term works directly on the state estimate to correct for estimation error. Accurate A/F ratio control has been demonstrated experimentally for a number of the members of this observer family using both CFI and MPI manifolds. Because these observers operate with a closed loop, they are much less susceptable to modelling error than the open loop (or feedforward) observers which may be found in the literature. Moreover they are naturally redundant and thus failure of one sensor will not entail complete engine control system failure or even a performance degradation.

A new type of sensor, a port air mass flow sensor, has been demonstrated to give more accurate $A / F$ ratio control than is possible with conventional MAFt sensors. It is thought that this sensor will become more attractive as legislation pushes forward the emission limits of SI engines.

\section{Nomenclature}

The following symbols are used in this paper:

$\begin{array}{ll}\mathrm{t} & \text { time (sec) } \\ \theta & \text { crank angle (degrees) } \\ \alpha & \text { throttle plate angle (degrees) } \\ \mathrm{n} & \text { engine speed (rpm/1000 or } \mathrm{krpm} \text { ) } \\ \mathrm{p}_{\mathrm{a}} & \text { pressure in front of throttle plate (bar) } \\ \mathrm{T}_{\mathrm{a}} & \text { temperature in front of throttle plate (Kelvin) } \\ \mathrm{p}_{\mathrm{i}} & \text { absolute manifold pressure (bar) } \\ \mathrm{T}_{\mathrm{i}} & \text { intake manifold temperature (degrees Kelvin) } \\ \mathrm{m}_{\mathrm{at}} & \text { air mass flow past throttle plate }(\mathrm{kg} / \mathrm{sec}) \\ \mathrm{m}_{\mathrm{ap}} & \text { air mass flow into intake port }(\mathrm{kg} / \mathrm{sec}) \\ \mathrm{m}_{\mathrm{fi}} & \text { injected fuel mass flow (kg/sec) } \\ \mathrm{m}_{\mathrm{iu}} & \text { injected fuel mass flow (precompensator) }(\mathrm{kg} / \mathrm{sec}) \\ \mathrm{m}_{\mathrm{ff}} & \text { fuel film mass flow (kg/sec) } \\ \mathrm{X} & \text { proportion of fuel deposited on intake manifold }\end{array}$

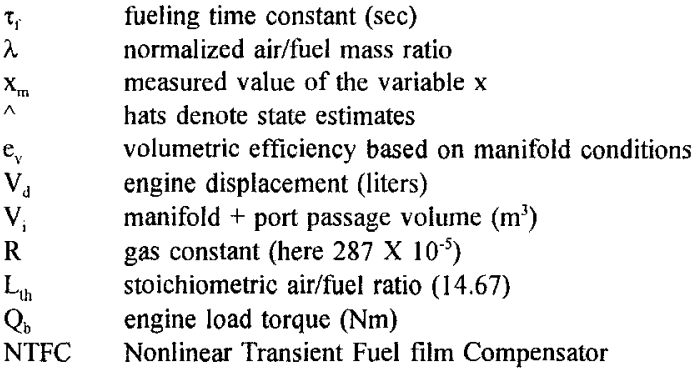

\section{References}

[1] Hendricks, E., Jensen, M., Kaidantzis, P., Rasmussen, P., and Vesterholm, T., "Transient A/F Ratio Errors in Conventional SI Engine Controllers", SAE Technical Paper No. 930856, in SP-955, 1993

[2] Hendricks, E., Chevalier, A., Jensen, M., and Vesterholm, T., "Event Based Engine Control: Practical Problems and Solutions", SAE Technical Paper No. 950008, 1995.

[3] Hendricks, E., Vesterholm, T., and Sorenson, S. C., "Nonlinear, Closed Loop, SI Engine Control Observers", SAE Technical Paper No. $920237,1992$.

[4] Grizzle, J., Cook, J., and Milam, W., "Improved Cylinder Air Charge Estimation for Transient Air Fuel Ratio Control", Proc. 1994 American Control Conference (ACC), Paper No. TM1-1:30, 1994.

[5] Schifsky, C., "Honey, I Shrunk the Airflow Sensor", Car Craft, p. 20, May, 1993

[6] Hendricks, E., and Sorenson, S. C., "Mean Value Modelling of Spark Ignition Engines", SAE Technical Paper No. 900616, 1990.

[7] Hendricks, E., Chevalier, A., Jensen, M., Sorenson, S. C., Trumpy, D., and Asik, J., "Modelling of the Manifold Filling Dynamics", SAE Technical Paper No. 960037, 1996.

[8] Moskwa, J. J., and Hedrick, J. K., "Automotive Engine Modeling for Real Time Control Applications", 1987 ACC, Paper No. WA1011:00, 1987.

[9] Crossely, P. R., and Cook, J. A., "A Nonlinear Engine Model for Drivetrain System Development", IEEE International Conference "Control 91", Conference Publication No. 332, Vol. 2, pp 921-921, Edinburgh, U. K., March, 1991.

[10] Adida, J., and Claude, D., "Spark Ignition Engines and Pollution Emission: New Approaches in Modelling and Control", Int. J. of Vehicle Design, Vol. 15, Nos. 3/4/5, 1994

[11] Hendricks, E., and Sorenson, S. C., "SI Engine Controls and Mean Value Engine Modelling", SAE Technical Paper No. 910258, 1991.

[12] Benninger, N. F., and Plapp, G., "Requirements and Performance of Engine Management Systems Under Transient Conditions", SAE Technical Paper No. 910083, 1991.

[13] Achleitner, E., Werner, H,., Koch, A., and Schürz, "Electronic Engine Control System for Gasoline Engines for LEV and ULEV Standards", SAE Technical Paper No. 940479, 1995.

[14] Vesterholm, T., and Hendricks, E., "SI Engine Observers Realized Using Optimized Integration Algorithms", 12th IFAC World Congress on Automatic Control, Sidney Australia, July, 1993.

[15] Safanov, M. G., and Athens, M., "Robustness and Computational Aspects of Nonlinear Stochastic Estimators and Regulators", IEEE Trans. on Automatic Control, Vol. AC.23, No.4, p. 717, 1981

[16] Lillelund, J., and Hendricks, E., "A PC Engine Control Development System", SAE Technical Paper No. 910259, 1991.

[17] Choi, Sei-Bum, Won, M., and Hedrick, J. K., "Fuel-Injection Control of SI Engines", Proc. 33rd Conf. on Dec. and Control (CDC), Lake Buena Vista, FL, Dec., 1994.

[18] Shayler, P. J., and Goodman, M. S., "Mixture Control with Air-Flow Anticipation Using Neural Networks", Paper No. 96AE025, 29th Int Symp. on Auto. Electro., Florence, Italy, June, 1996.

[19] Fekete, N. P., Powell, J. D., Nester, U., and Gruden, I., "ModelBased Air-Fuel Ratio Control of a Lean Multi-Cylinder Engine", SAE Technical Paper No. 950846, 1995. 